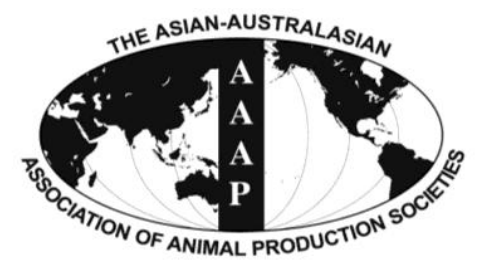

Asian-Aust. J. Anim. Sci.

Vol. 25, No. 6 : 845 - 851

June 2012

www.ajas.info

http://dx.doi.org/10.5713/ajas.2011.11517

\title{
Effect of Arachidonic Acid-enriched Oil Diet Supplementation on the Taste of Broiler Meat
}

\author{
H. Takahashi*, K. Rikimaru ${ }^{1}$, R. Kiyohara ${ }^{2}$ and S. Yamaguchi ${ }^{2}$ \\ Animal Breeding and Reproduction Research Division \\ National Institute of Livestock and Grassland Science, Tsukuba, 305-0901, Japan
}

\begin{abstract}
To elucidate the relationship between the arachidonic acid (AA) content and the taste of broiler meat, the effects of AAenriched oil (AAO) supplements on the fatty acid content and sensory perceptions of thigh meat were evaluated. Four types of oil, including corn oil (CO), a 1:1 mixture of AAO and palm oil (PO) (1/2 AAO), a 1:3 mixture of AAO and PO (1/4 AAO), and a 1:7 mixture of AAO and PO (1/8 AAO) were prepared. Each type of oil was mixed with silicate at a ratio of 7:3, and added to the diet at a final proportion of $5 \%$ of fresh matter. Broiler chickens were fed these diets for $1 \mathrm{wk}$ before slaughter. In thigh meat, the AA content of the $1 / 2$ and $1 / 4$ AAO groups was significantly higher than that of the CO group. The AA content in thigh meat (y, mg/g) increased linearly with increasing dietary AAO content $\left(x, g / 100 \mathrm{~g}\right.$ of diet), according to the equation $\mathrm{y}=0.5674+0.4596 \mathrm{x}\left(\mathrm{r}^{2}=0.8454\right)$. The content of other fatty acids was not significantly different among the 4 diet groups. Sensory evaluation showed that the flavor intensity, umami (L-glutamate taste), kokumi (continuity, mouthfulness, and thickness), and aftertaste of the 1/2 and 1/4 AAO groups were significantly higher than that of the $\mathrm{CO}$ group. There were significant positive correlations between AA content in thigh meat and the flavor intensity, total taste intensity, umami, and aftertaste. These data suggest that the taste of broiler meat can be improved by the amount of dietary AA supplementation. (Key Words: Broiler Chicken, Arachidonic Acid, Feed Supplement, Fatty Acid Content, Sensory Evaluation)
\end{abstract}

\section{INTRODUCTION}

Most of the chicken meat of the world is obtained from several fast-growing broiler strains provided by commercial breeding companies that use intensive fattening systems to ensure high meat yields; however, some consumers in the Asia region are willing to pay a high retail price for better flavor chicken meat. In Japan, some native chickens are now being used to breed brand chickens. Brand chickens using native chickens are referred to as Jidori (Japanese old style native), a name that helps consumers to differentiate this chicken from the others on offer. The Hinai-dori is a slow-growing breed of chicken native to Akita Prefecture, in northern Honshu Island, Japan. The taste of Hinai-dori meat is well recognized and the meat has been used for a

\footnotetext{
* Corresponding Author: H. Takahashi. Tel: +81-29-838-8623, Fax: +81-29-838-8606, E-mail: naoe@ affrc.go.jp

${ }^{1}$ Livestock Experiment Station, Akita Prefectural Agriculture Forestry and Fisheries Research Center, Daisen 019-1701, Japan.

${ }^{2}$ Oils and Fats Fundamental Technology Laboratory, J-Oil Mills, Inc., Yokohama 230-0053, Japan.

Submitted Dec. 28, 2011; Accepted Feb. 7, 2012; Revised Feb. 21, 2012
}

long time. At present, $F_{1}$ chickens produced by crossing Hinai-dori sires with Rhode Island Red dams have been commercialized as Hinai-jidori chicken, a very popular brand chicken on the Japanese market (Rikimaru and Takahashi, 2007).

A sensory evaluation report revealed increased taste of the Hinai-jidori chicken over broiler chickens (Hatakeyama et al., 1983). In a previous study (Rikimaru and Takahashi, 2010), to define candidate substances related to the taste of Hinai-jidori chicken meat, Hinai-jidori and broiler chickens were reared under identical environmental and time conditions. The results revealed that higher arachidonic acid (AA, 20:4n-6) content was a characteristic feature of Hinai-jidori chicken.

AA is a polyunsaturated fatty acid (PUFA) present in animal lipids. AA is present at the head of the "arachidonic acid cascade" which includes more than 20 different eicosanoid-mediated signaling pathways that control a wide array of cellular functions, particularly those regulating inflammation, immunity, and the central nervous system (Brash, 2001). Recently, we reported that PUFA, including AA, enhanced the umami (L-glutamate taste) and kokumi 
(continuity, mouthfulness, and thickness; Yamamoto et al., 2009) flavor of foods (Yamaguchi et al., 2005, 2007; Kiyohara et al., 2009).

In a recent study (Kiyohara et al., 2011), Hinai-jidori chickens were administered diets containing 3 different oils (palm, corn, and AA-enriched oil) during rearing, followed by evaluation of the meat by biochemical and sensory analyses, to elucidate the relationship between the AA content and taste of Hinai-jidori meat. The data suggested that AA content in Hinai-jidori meat could be increased by AA diet supplements, and that Hinai-jidori meat and soup with higher levels of AA content had a much better perception of the taste than that with low AA content. In addition, it was demonstrated that glutamic acid (Glu) and inosine 5'-monophosphate (IMP), which were until now thought to be key contributors to umami taste (Yamaguchi and Ninomiya, 2000), might not be directly related to the flavor of chicken soup.

In the present study, we examine whether AA dietary supplements can improve the taste of broiler chickens, and define the optimal level of AA supplements for improving the taste of broiler meat. For this purpose, the dietary AA content was changed systematically to elucidate the relationship between the AA content and taste of broiler meat by biochemical and sensory analyses.

\section{MATERIALS AND METHODS}

\section{Bird housing and treatment}

All animals received humane care as outlined in the Guidelines for Proper Conduct of Animal Experiments (Science Council of Japan, 2006). Broiler eggs of Ross 308 strain were obtained from a local trading company (Nippon Chunky Co., Okayama, Japan). Twenty female chicks, hatched on the same day in the same incubator, were raised to 2 wks of age in temperature-controlled, wire-floored, 4-tier battery cages. At 2 wks of age, the twenty females were moved to group cages and evenly divided into 4 dietary groups described below ( $\mathrm{n}=5$ per group). A commercial diet was used for chicks up to 4 wks of age, which contained $21 \% \mathrm{CP}$ and 3,100 $\mathrm{kcal} / \mathrm{kg} \mathrm{ME}$. A second diet used for chicks from 4 to 7 wks of age contained $17 \%$ $\mathrm{CP}$ and 3,250 kcal/kg ME. Feed and water were provided ad libitum.

Corn oil (CO, J-Oil Mills, Inc., Tokyo, Japan), palm oil $\left(\mathrm{PO}\right.$, iodine value $=60$, melting point $=15^{\circ} \mathrm{C}$, J-Oil Mills, Inc.), and AA-enriched oil (AAO, SUNTGA40S, Nippon Suisan Co., Tokyo, Japan) were used in the dietary supplements. SUNTGA40S was extracted from a biomass of submerged fermented Mortiere alpine and refined by high purification processes. SUNTGA40S contained $41.5 \%$ AA, $0.1 \%$ eicosapentaenoic acid and no docosahexaenoic acid. From these, 4 types of oil mixtures were prepared, i) $\mathrm{CO}$, ii) a 1:1 wt/wt mixture of AAO/PO (1/2 AAO), iii) a $1: 3 \mathrm{wt} / \mathrm{wt}$ mixture of AAO/PO (1/4 AAO), and iv) a $1: 7$ wt/wt mixture of AAO/PO (1/8 AAO). Each of these oils were mixed in a volume ratio of 7:3 with silicate (TIXOSIL 38A, Rhodia Silica Korea Co., Seoul, South Korea). To prepare the 4 experimental diets, the mixtures were added to the second diet to a final proportion of $5 \%$ of fresh matter (3.5\% equivalent of each oil). Diet fatty acid profiles are shown in Table 1.

The CO, 1/2 AAO, 1/4 AAO, and 1/8 AAO diets were provided ad libitum from 7 to 8 wks of age. Water was

Table 1. Content and composition of fatty acids in experimental diets

\begin{tabular}{|c|c|c|c|c|c|c|c|c|c|c|}
\hline \multirow[t]{2}{*}{ Fatty acid } & \multicolumn{2}{|c|}{ Second diet } & \multicolumn{2}{|c|}{ Corn oil } & \multicolumn{2}{|c|}{$\begin{array}{l}\text { 1/8-Arachidonic } \\
\text { acid-enriched } \\
\text { oil }\end{array}$} & \multicolumn{2}{|c|}{$\begin{array}{c}\text { 1/4-Arachidonic } \\
\text { acid-enriched } \\
\text { oil } \\
\end{array}$} & \multicolumn{2}{|c|}{$\begin{array}{l}\text { 1/2-Arachidonic } \\
\text { acid-enriched } \\
\text { oil }\end{array}$} \\
\hline & $\begin{array}{l}g / 100 \mathrm{~g} \\
\text { of diet }\end{array}$ & $\begin{array}{c}\% \text { fatty } \\
\text { acid }\end{array}$ & $\begin{array}{l}g / 100 \mathrm{~g} \\
\text { of diet }\end{array}$ & $\begin{array}{c}\% \text { fatty } \\
\text { acid }\end{array}$ & $\begin{array}{c}\mathrm{g} / 100 \mathrm{~g} \\
\text { of diet }\end{array}$ & $\begin{array}{c}\% \text { fatty } \\
\text { acid }\end{array}$ & $\begin{array}{l}\mathrm{g} / 100 \mathrm{~g} \\
\text { of diet }\end{array}$ & $\begin{array}{c}\% \text { fatty } \\
\text { acid }\end{array}$ & $\begin{array}{l}\mathrm{g} / 100 \mathrm{~g} \\
\text { of diet }\end{array}$ & $\begin{array}{c}\% \text { fatty } \\
\text { acid }\end{array}$ \\
\hline Crude fat $(\%)$ & 3.4 & - & 6.9 & - & 6.9 & - & 6.9 & - & 6.9 & - \\
\hline Myristic acid (C14:0) & 0.01 & 0.3 & 0.01 & 0.1 & 0.04 & 0.6 & 0.04 & 0.6 & 0.03 & 0.5 \\
\hline Palmitic acid (C16:0) & 0.45 & 13.2 & 0.83 & 12.0 & 1.76 & 25.6 & 1.63 & 23.2 & 1.37 & 19.8 \\
\hline Palmitoleic acid (C16:1n-9) & 0.02 & 0.5 & 0.02 & 0.3 & 0.02 & 0.3 & 0.02 & 0.3 & 0.02 & 0.3 \\
\hline Stearic acid (C18:0) & 0.11 & 3.1 & 0.16 & 2.4 & 0.27 & 3.9 & 0.28 & 3.9 & 0.30 & 4.3 \\
\hline Oleic acid (C18:1n-9) & 1.07 & 31.4 & 2.03 & 29.4 & 2.31 & 33.5 & 2.16 & 30.7 & 1.87 & 27.2 \\
\hline Linoleic acid (C18:2n-6) & 1.45 & 42.6 & 3.45 & 50.0 & 1.79 & 26.0 & 1.79 & 25.4 & 1.78 & 25.8 \\
\hline$\gamma$-Linolenic acid (C18:3n-6) & 0.00 & 0.0 & 0.00 & 0.0 & 0.01 & 0.2 & 0.02 & 0.4 & 0.05 & 0.7 \\
\hline$\alpha$-Linolenic acid (C18:3n-3) & 0.07 & 1.9 & 0.09 & 1.4 & 0.08 & 1.2 & 0.08 & 1.2 & 0.08 & 1.2 \\
\hline Arachidic acid $(\mathrm{C} 20: 0)$ & 0.02 & 0.7 & 0.04 & 0.5 & 0.04 & 0.6 & 0.04 & 0.6 & 0.04 & 0.6 \\
\hline Eicosatrienoic acid $(C 20: 3 n-3+n-6)$ & 0.00 & 0.0 & 0.00 & 0.0 & 0.01 & 0.2 & 0.03 & 0.4 & 0.06 & 0.8 \\
\hline Arachidonic acid (C20:4n-6) & 0.00 & 0.0 & 0.00 & 0.0 & 0.19 & 2.8 & 0.39 & 5.5 & 0.77 & 11.2 \\
\hline Lignoceric acid (C24:0) & 0.00 & 0.0 & 0.01 & 0.1 & 0.04 & 0.6 & 0.10 & 1.4 & 0.15 & 2.2 \\
\hline Unidentified FA & 0.21 & 6.2 & 0.26 & 3.8 & 0.32 & 4.6 & 0.45 & 6.4 & 0.37 & 5.4 \\
\hline
\end{tabular}


provided ad libitum. The final sample size of the CO diet group was 4 , due to the accidental death of 1 chicken.

\section{Sample preparation and storage}

At $8 \mathrm{wks}$ of age, the chickens were fasted for $18 \mathrm{~h}$, and then slaughtered in the Akita Prefectural Agriculture Forestry and Fisheries Research Center at the same day. The chickens were bled and plucked, and their carcasses were manually eviscerated and washed, followed by immediate cooling in ice-cold water until a temperature of $8^{\circ} \mathrm{C}$ was reached. They were then removed from the water and allowed to drain for $30 \mathrm{~min}$. Carcasses were dissected and the thigh meat was deboned. After skin removal, thigh meat was placed in a reclosable plastic bag (G-4, Seisan-nipponsha Co., Tokyo, Japan). The film of the plastic bag has a 0.1-mm-thick single polyethylene layer. The air in the bag was manually expressed and the bag was closed. Meat samples were stored at $-30^{\circ} \mathrm{C}$ until further analysis.

Determination of moisture, crude fat, free amino acids, inosine 5'-monophosphate, and fatty acid content of meat

Moisture content was determined using a freeze dryer (RL-B07, Kyowa Vacuum Engineering Co., Tokyo, Japan). Crude fat content was determined according to the diethyl ether extraction method 1-5-1996 of the Association of Official Analytical Chemists (1990).

The free amino acids (FAA) content was determined by homogenizing $5 \mathrm{~g}$ of minced meat with $22.5 \mathrm{ml}$ of $0.1 \%$ 2-mercaptoethanol and $3 \mathrm{ml}$ of $50 \%$ (wt/vol) trichloroacetic acid. Homogenates were allowed to stand for more than $3 \mathrm{~h}$ and centrifuged at $10,000 \times \mathrm{g}$ for $20 \mathrm{~min}$ at $4{ }^{\circ} \mathrm{C}$. The supernatant was collected and filtered through a $1.0 \mu \mathrm{m}$ filter paper (\#5C, Advantec Toyo Co., Tokyo, Japan). The $\mathrm{pH}$ of the filtrate was adjusted to 2.3 , and the FAA in the meat samples were analyzed using an amino acid analyzer (JLC-500/V, JEOL Co., Tokyo, Japan).

The IMP content was determined by homogenizing $5 \mathrm{~g}$ of minced meat with $15 \mathrm{ml}$ of distilled water for $2 \mathrm{~min}$. The homogenate was centrifuged at $10,000 \times \mathrm{g}$ at $4^{\circ} \mathrm{C}$ for $20 \mathrm{~min}$. The supernatant was filtered through a $0.45 \mu \mathrm{m}$ membrane filter (Millex-HV, Millipore Co., Billerica, USA). The filtrate was analyzed using HPLC (1100, Agilent Technologies Co., Tokyo, Japan).

To determine fatty acid profiles, we extracted lipids from $0.1 \mathrm{~g}$ of each minced meat sample using $3 \mathrm{ml}$ of chloroform:methanol (2:1, vol/vol) according to the method described by Iverson et al. (2001). The extract was thoroughly mixed with $1.5 \mathrm{ml}$ of hexane. Following the addition of $200 \mu \mathrm{l}$ of $2 \mathrm{M}$ potassium hydroxide in methanol, the contents were vortexed for $30 \mathrm{~s}$. A $2 \mathrm{ml}$ aliquot of saturated sodium chloride solution was added and mixed thoroughly. The sample was then centrifuged at $1,000 \times \mathrm{g}$ for
$5 \mathrm{~min}$, and the supernatant containing fatty acid methyl esters was recovered. The fatty acid methyl esters were separated using a GC2010 Gas Chromatograph (Shimadzu Co., Kyoto, Japan) and a capillary column (DB-23, Shimadzu) (length, $30 \mathrm{~m}$; internal diameter, $0.25 \mathrm{~mm}$; film thickness, $0.25 \mu \mathrm{m})$. Helium carrier gas was used at a linear flow velocity of $35.4 \mathrm{~cm} / \mathrm{s}$. The column was set at an initial temperature of $80^{\circ} \mathrm{C}$ for $2 \mathrm{~min}$, which was then increased from 80 to $160^{\circ} \mathrm{C}$ at $35^{\circ} \mathrm{C} / \mathrm{min}$, and again from 160 to $185^{\circ} \mathrm{C}$ at $2^{\circ} \mathrm{C} / \mathrm{min}$, followed by an increase of $10^{\circ} \mathrm{C} / \mathrm{min}$ to a maximum temperature of $230^{\circ} \mathrm{C}$, which was maintained for $9 \mathrm{~min}$. Other conditions were as follows: injection port temperature, $250^{\circ} \mathrm{C}$; flame ionization detector temperature, $250^{\circ} \mathrm{C}$; helium flow rate, $1.49 \mathrm{ml} / \mathrm{min}$. Fatty acids were identified by comparison of retention times with those of the FAME Mix Equity1 standard (Sigma-Aldrich Co., St. Louis, USA). The fatty acid contents were also determined by the official method of the Japan Oil Chemists' Society (2009) using an internal standard (methyl tricosanoate, Sigma-Aldrich Co.).

\section{Sensory analysis}

Steamed minced meat preparation: Frozen thigh meat stored for six mo in plastic bags was thawed under running water $\left(25^{\circ} \mathrm{C}\right)$, the skin was removed, and the meat minced twice in a mincer (BK-220, Bonny Co, Osaka, Japan) using a $3.2 \mathrm{~mm}$ diameter sieve. Minced meat samples within each experiment group were equally mixed. The minced meat was repackaged in vacuum bag $(80 \mathrm{~g} / \mathrm{bag})$ and stored at $-30^{\circ} \mathrm{C}$ until used for sensory evaluation. The steps of thawing, mincing, and re-freezing were performed at the same day. Just before cooking, minced meat in plastic bags was thawed under running water. For sensory evaluation, ten $\mathrm{g}$ of minced meat taken from a $80 \mathrm{~g}$ package was divided into eight plastic round containers, covered with a lid $(8.1 \mathrm{~cm}$ diameter $\times 3.4 \mathrm{~cm}$ height; cat. no. 1741 , Inomata Chemical Co., Tokyo, Japan), heated in a $500 \mathrm{~W}$ microwave oven (NE-P7, Panasonic Co, Osaka, Japan) for $90 \mathrm{~s}$, and immediately served to each panelist per a pair of samples. Sensory evaluation was conducted using steamed minced meat in order to eliminate the effect of meat appearance and texture. Samples were treated in an unbiased manner.

Sensory evaluation: Sensory evaluation was performed by 28 panelists who were experienced tasting steamed minced meat in our previous study (Kiyohara et al., 2011) within the Oils and Fats Fundamental Technology Laboratory, J-Oil Mills, Inc. Steamed minced meat from the 4 diet groups were tested in pairs, $\mathrm{CO}-1 / 2 \mathrm{AAO}, \mathrm{CO}-1 / 4$ AAO, CO-1/8 AAO, 1/4 AAO-1/2 AAO, 1/8 AAO-1/2 AAO, and 1/8 AAO-1/4 AAO. Panelists chose one sample ballot with random 3-digit codes per session. The reference and test samples were served to panelists according to the code. Water was provided for palate cleaning. Of the 28 
panelists, eight panelists randomly selected per session evaluated seven parameters, flavor intensity (perceived intensity of mixed tastes with retronasal aroma), total taste intensity (perceived intensity of mixed tastes), sweetness, sourness, umami, kokumi, and aftertaste. Panelists recorded whether the test sample was comparatively stronger (score $=+2,+1)$ or weaker (score $=-1,-2$ ) than the reference sample (score $=0$ ). Sensory analyses were performed in a sensory panel room at $25^{\circ} \mathrm{C}, 4,200 \mathrm{~lx}$, and $52 \mathrm{~dB}$ with good ventilation.

\section{Statistical analysis}

All statistical analyses were performed using SPSS 15.0J for Windows software (SPSS Inc., Chicago, USA). Except for sensory evaluation data, comparisons among the treatment means were assessed by Scheffe's multiple comparison test of non-parametric method at a significance level of $p<0.05$. Sensory evaluation data were analyzed by Wilcoxson's signed rank test, at a significance level of $\mathrm{p}<0.05$ or $\mathrm{p}<0.01$. Pearson product-moment correlation coefficients ( $r$ ) between sensory data and biochemical substances that showed significant differences in their content among the 4 dietary groups were determined. Relationships between AAO content in diet and AA content in thigh meat of broiler chicken were evaluated using simple linear regression analysis.

\section{RESULTS}

There were no significant differences in the moisture and crude fat content among the groups (Table 2). Among the amino acids, the only significant difference $(\mathrm{p}<0.05)$ was a higher arginine content in the $1 / 8 \mathrm{AAO}$ group than in the $\mathrm{CO}$ group (Table 2).

The AA content of meat from the 1/2 AAO group was significantly $(p<0.05)$ higher than those from the $\mathrm{CO}$ and 1/8 AAO groups (Table 3). Simple linear regression analysis showed a positive correlation $(y=0.5674+0.4596 x$, $\left.\mathrm{r}^{2}=0.8454, \mathrm{p}=0.000\right)$ between dietary AAO content and AA content in thigh meat.

Table 2. Moisture, crude fat, free amino acids, and inosine 5'-monophosphate content in thigh meat of broiler chickens fed experimental $\operatorname{diets}^{1}$

\begin{tabular}{|c|c|c|c|c|}
\hline Item & Corn oil & $\begin{array}{l}\text { 1/8-Arachidonic } \\
\text { acid-enriched oil }\end{array}$ & $\begin{array}{l}\text { 1/4-Arachidonic } \\
\text { acid-enriched oil }\end{array}$ & $\begin{array}{l}\text { 1/2-Arachidonic } \\
\text { acid-enriched oil }\end{array}$ \\
\hline $\mathrm{n}$ & 4 & 5 & 5 & 5 \\
\hline Moisture (\%) & $70.4 \pm 0.3$ & $71.0 \pm 0.6$ & $72.3 \pm 0.3$ & $71.2 \pm 0.7$ \\
\hline Crude fat $(\%)$ & $10.2 \pm 0.6$ & $9.4 \pm 0.9$ & $8.4 \pm 0.3$ & $9.7 \pm 0.8$ \\
\hline \multicolumn{5}{|l|}{ Free amino acids (mg/100 g) } \\
\hline Aspartic acid & $15.3 \pm 2.1$ & $17.0 \pm 1.9$ & $14.2 \pm 3.5$ & $14.0 \pm 1.4$ \\
\hline Threonine & $12.3 \pm 1.7$ & $14.4 \pm 1.9$ & $11.6 \pm 2.3$ & $12.8 \pm 1.5$ \\
\hline Serine & $25.0 \pm 4.3$ & $25.2 \pm 2.2$ & $23.8 \pm 3.7$ & $25.8 \pm 2.6$ \\
\hline Asparagine & $7.5 \pm 1.3$ & $8.2 \pm 1.3$ & $8.0 \pm 1.6$ & $6.4 \pm 1.7$ \\
\hline Glutamic acid & $38.8 \pm 8.1$ & $42.0 \pm 4.8$ & $35.4 \pm 4.6$ & $34.8 \pm 2.7$ \\
\hline Glutamine & $75.3 \pm 12.1$ & $88.0 \pm 15.4$ & $86.2 \pm 7.7$ & $88.8 \pm 8.0$ \\
\hline Proline & $9.8 \pm 2.4$ & $14.0 \pm 1.6$ & $11.6 \pm 2.1$ & $10.4 \pm 1.3$ \\
\hline Glycine & $17.5 \pm 2.4$ & $18.8 \pm 1.5$ & $17.0 \pm 2.5$ & $16.8 \pm 2.2$ \\
\hline Alanine & $31.0 \pm 4.5$ & $33.8 \pm 4.3$ & $31.2 \pm 6.7$ & $30.8 \pm 3.9$ \\
\hline Methionine & $7.5 \pm 1.3$ & $8.6 \pm 1.7$ & $7.2 \pm 2.6$ & $6.8 \pm 0.8$ \\
\hline Cysteine & $-*$ & $-*$ & $-*$ & $-*$ \\
\hline Methionine & $4.8 \pm 1.0$ & $5.4 \pm 1.1$ & $4.4 \pm 1.1$ & $4.4 \pm 0.5$ \\
\hline Isoleucine & $5.0 \pm 0.8$ & $5.6 \pm 1.1$ & $4.6 \pm 1.5$ & $4.2 \pm 0.8$ \\
\hline Leucine & $10.3 \pm 1.3$ & $11.8 \pm 2.4$ & $9.4 \pm 3.0$ & $9.8 \pm 1.9$ \\
\hline Tyrosine & $7.0 \pm 0.8$ & $8.2 \pm 1.6$ & $6.6 \pm 2.6$ & $7.0 \pm 1.2$ \\
\hline Phenylalanine & $5.8 \pm 1.0$ & $6.4 \pm 1.1$ & $5.0 \pm 1.6$ & $5.2 \pm 0.8$ \\
\hline Histidine & $6.3 \pm 0.5$ & $7.8 \pm 1.3$ & $6.4 \pm 1.7$ & $6.0 \pm 1.0$ \\
\hline Lysine & $38.0 \pm 27.7$ & $24.8 \pm 3.0$ & $16.8 \pm 4.3$ & $19.6 \pm 7.2$ \\
\hline Tryptophan & $1.8 \pm 0.5$ & $2.0 \pm 0.0$ & $2.2 \pm 0.4$ & $1.6 \pm 0.5$ \\
\hline Arginine & $20.5 \pm 3.7^{b}$ & $32.6 \pm 7.2^{\mathrm{a}}$ & $23.8 \pm 5.3^{\mathrm{ab}}$ & $24.6 \pm 4.3^{\mathrm{ab}}$ \\
\hline Total free amino acids & $339.0 \pm 57.3$ & $374.6 \pm 41.7$ & $325.4 \pm 53.0$ & $329.8 \pm 29.3$ \\
\hline Inosine 5'-monophosphate (mg/100 g) & $88.2 \pm 13.7$ & $53.3 \pm 20.3$ & $68.0 \pm 24.4$ & $84.8 \pm 10.2$ \\
\hline
\end{tabular}

${ }^{\mathrm{a}, \mathrm{b}}$ Means within a row with no common superscript differ statistically $(\mathrm{p}<0.05) .{ }^{*}$ Below measurable limits. ${ }^{1}$ Values are mean \pm SD. 
Table 3. Fatty acid content $(\mathrm{mg} / \mathrm{g})$ of thigh meat of broiler chickens fed experimental diets ${ }^{1}$

\begin{tabular}{lcccc}
\hline & Corn oil & $\begin{array}{c}\text { 1/8-Arachidonic acid- } \\
\text { enriched oil }\end{array}$ & $\begin{array}{c}\text { 1/4-Arachidonic acid- } \\
\text { enriched oil }\end{array}$ & $\begin{array}{c}1 / 2 \text {-Arachidonic acid- } \\
\text { enriched oil }\end{array}$ \\
\hline Myristic acid (C14:0) & $0.45 \pm 0.03$ & $0.43 \pm 0.03$ & $0.39 \pm 0.06$ & $0.44 \pm 0.05$ \\
Palmitic acid (C16:0) & $14.12 \pm 0.83$ & $13.46 \pm 0.59$ & $11.91 \pm 1.62$ & $13.04 \pm 1.57$ \\
Palmitoleic acid (C16:1n-9) & $3.46 \pm 0.27$ & $3.35 \pm 0.18$ & $2.67 \pm 0.37$ & $2.78 \pm 0.47$ \\
Heptadecanoic acid (C17:0) & $0.11 \pm 0.01$ & $0.09 \pm 0.01$ & $0.07 \pm 0.03$ & $0.11 \pm 0.01$ \\
Stearic acid (C18:0) & $3.75 \pm 0.21$ & $3.51 \pm 0.18$ & $3.38 \pm 0.43$ & $3.79 \pm 0.27$ \\
Oleic acid (C18:1n-9) & $28.48 \pm 2.26$ & $26.47 \pm 1.30$ & $22.96 \pm 3.28$ & $24.65 \pm 3.10$ \\
Linoleic acid (C18:2n-6) & $11.11 \pm 0.89$ & $8.58 \pm 0.58$ & $7.90 \pm 1.23$ & $8.75 \pm 0.81$ \\
$\gamma$-Linolenic acid (C18:3n-6) & $0.11 \pm 0.01$ & $0.10 \pm 0.01$ & $0.09 \pm 0.01$ & $0.13 \pm 0.01$ \\
Linolenic acid (C18:3n-3) & $0.65 \pm 0.06$ & $0.59 \pm 0.05$ & $0.54 \pm 0.10$ & $0.61 \pm 0.06$ \\
Eicosenoic acid (C20:1n-9) & $0.22 \pm 0.02$ & $0.21 \pm 0.01$ & $0.18 \pm 0.03$ & $0.20 \pm 0.02$ \\
Eicosadienoic acid (C20:2n-6) & $0.12 \pm 0.01$ & $0.14 \pm 0.01$ & $0.12 \pm 0.01$ & $0.13 \pm 0.01$ \\
Eicosatrienoic acid (C20:3n-3+n-6) & $0.13 \pm 0.01$ & $0.14 \pm 0.01$ & $0.15 \pm 0.01$ & $0.18 \pm 0.01$ \\
Arachidonic acid (C20:4n-6) & $0.57 \pm 0.05^{\mathrm{b}}$ & $0.76 \pm 0.03^{\mathrm{b}}$ & $0.98 \pm 0.05^{\mathrm{ab}}$ & $1.37 \pm 0.10^{\mathrm{a}}$ \\
Arachidic acid (C24:0) & $0.10 \pm 0.01$ & $0.11 \pm 0.01$ & $0.11 \pm 0.00$ & $0.10 \pm 0.00$ \\
Docosahexaenoic acid (C22:6n-3) & $0.13 \pm 0.01$ & $0.15 \pm 0.00$ & $0.16 \pm 0.01$ & $0.15 \pm 0.01$ \\
Unidentified fatty acids & $0.92 \pm 0.12$ & $0.80 \pm 0.13$ & $0.78 \pm 0.18$ & $0.86 \pm 0.18$ \\
\hline
\end{tabular}

${ }_{\mathrm{a}, \mathrm{b}}$ Means within a row with no common superscript differ statistically $(\mathrm{p}<0.05) .{ }^{1}$ Values are mean \pm SD.

In a pairwise comparison between the $\mathrm{CO}$ and $1 / 4 \mathrm{AAO}$ groups, the parameters of flavor intensity, umami, kokumi, and aftertaste of meat from the 1/4 AAO group were scored significantly $(p<0.05)$ higher than those of meat from the CO group (Table 4). In a similar pairwise comparison, the flavor intensity, total taste intensity, umami, kokumi, and aftertaste of $1 / 2$ AAO meat were found to be significantly $(\mathrm{p}<0.05)$ higher than that of $\mathrm{CO}$ meat. In a pairwise comparison between the 1/4 AAO and 1/2 AAO groups, the total taste intensity and sourness of $1 / 2$ AAO meat was significantly $(\mathrm{p}<0.05)$ higher than that of $1 / 4$ AAO meat.

Since the content of two meat components, arginine and AA, was significantly $(\mathrm{p}<0.05)$ different among test groups, correlation coefficients $(r)$ were calculated between sensory data, and arginine and AA content (Table 5). There were significant positive correlations $(\mathrm{p}<0.05)$ between AA content and flavor intensity, total taste intensity, umami, and aftertaste of thigh meat, while there was no correlation between arginine content and any of the sensory parameters.

\section{DISCUSSION}

There is widespread agreement for the existence of sweet, sour, salty, bitter, and umami taste perceptions in humans. Recent studies have suggested that fats and oils can be implicated in gustatory sensing (Chaudhari and Roper, 2010). Although dietary fat is predominantly in the form of triglycerides, which are not effective taste stimuli,

Table 4. Sensory evaluation of steamed minced meat of broiler chickens fed experimental diets

\begin{tabular}{lcccccc}
\hline & \multicolumn{3}{c}{ Pair $^{2}$} \\
\cline { 2 - 7 } Item $^{1}$ & $\mathrm{CO}$ & $\mathrm{CO}$ & $\mathrm{CO}$ & $1 / 4 \mathrm{AAO}$ & $1 / 8 \mathrm{AAO}^{7}$ & $\begin{array}{c}1 / 8 \mathrm{AAO}^{7} \\
\end{array}$ \\
\cline { 2 - 7 } & $-1 / 8 \mathrm{AAO}^{3}$ & $-1 / 4 \mathrm{AAO}^{4}$ & $-1 / 2 \mathrm{AAO}^{5}$ & $-1 / 2 \mathrm{AAO}^{6}$ & $-1 / 2 \mathrm{AAO}^{7}$ & $-1 / 4 \mathrm{AAO}^{8}$ \\
\hline Flavor intensity & 0.63 & $0.63^{*}$ & $0.88^{*}$ & 0.25 & 0.13 & 0.25 \\
Total taste intensity & 0.25 & 0.63 & $1.00^{*}$ & $0.50^{*}$ & 0.38 & 0.00 \\
Sweetness & 0.50 & 0.38 & 0.38 & 0.25 & 0.25 & 0.13 \\
Sourness & 0.13 & 0.38 & 0.00 & $0.50^{*}$ & 0.13 & 0.00 \\
Umami & 0.50 & $0.63^{*}$ & $0.88^{* *}$ & 0.13 & 0.25 & 0.00 \\
Kokumi & 0.63 & $0.75^{*}$ & $0.50^{*}$ & 0.38 & 0.25 & 0.38 \\
Aftertaste & 0.50 & $0.75^{*}$ & $0.75^{*}$ & 0.25 & 0.13 & 0.50 \\
\hline
\end{tabular}

\footnotetext{
${ }^{1}$ Umami = L-glutamate taste; kokumi $=$ Continuity, mouthfulness, and thickness.

${ }^{2} \mathrm{CO}=\mathrm{Corn}$ oil $; 1 / 8,1 / 4$, and $1 / 2 \mathrm{AAO}=1 / 8,1 / 4$, and $1 / 2$ arachidonic acid-enriched oil.

${ }^{3}$ Average $1 / 8$ AAO score of each subject when CO score is $0 .{ }^{4}$ Average $1 / 4$ AAO score of each subject when CO score is 0 .

${ }^{5}$ Average $1 / 2 \mathrm{AAO}$ score of each subject when CO score is $0 .{ }^{6}$ Average $1 / 2 \mathrm{AAO}$ score of each subject when $1 / 4 \mathrm{AAO}$ score is 0 .

${ }^{7}$ Average $1 / 2$ AAO score of each subject when $1 / 8$ AAO score is $0 .{ }^{8}$ Average $1 / 4$ AAO score of each subject when $1 / 8$ AAO score is 0 .

$* \mathrm{p}<0.05$ and $* * \mathrm{p}<0.01$.
} 
Table 5. Correlations between sensory data, and arginine and arachidonic acid contents in thigh meat of broiler chickens

\begin{tabular}{lcc}
\hline Item $^{1}$ & Arginine $^{2}$ & Arachidonic acid $^{3}$ \\
\hline Flavor intensity & 0.00 & $0.39 * *$ \\
Total taste intensity & -0.25 & $0.29 *$ \\
Sweetness & 0.04 & 0.11 \\
Sourness & -0.27 & -0.09 \\
Umami & -0.02 & $0.37 *$ \\
Kokumi & 0.00 & 0.17 \\
Aftertaste & -0.01 & $0.31 *$ \\
\hline${ }^{1}$ Umami = L-glutamate taste; kokumi = Continuity, mouthfulness, and \\
thickness. \\
${ }^{2}$ Differences in arginine content estimated by pairwise comparison were \\
used to assess correlation. \\
${ }^{3}$ Differences in arachidonic acid content estimated by pairwise \\
comparison were used to assess correlation. \\
$*$ p $<0.05$ and ** $p<0.01$.
\end{tabular}

lingual lipase may yields free fatty acids (FFA) rapidly enough to enable detection by a fat sensor on the tongue surface (Kawai and Fushiki, 2003).

Gustatory transduction mechanisms for the detection of FFA have been described in humans, mice, and rats. For example, delayed rectifying potassium channels that are selective for FFA have been identified in isolated taste receptor cells from rat fungiform papillae (Gilbertson et al., 1997). The CD36 and the G-protein coupled receptors (i.e., GPR120 and GPR40) have recently identified as putative FFA taste receptors (Laugerette et al., 2005; Cartoni et al., 2010). Laugerette et al. (2005) showed that CD36 is expressed in some type II (sweet, bitter, and umami) receptor cells in mouse taste buds. Cartoni et al. (2010) reported that GPR120 and GPR40 are mainly expressed in Type II and Type I (salty) receptor cells, respectively. These data suggest that FFA may affect taste perception of sweet, bitter, umami, and salty based on taste receptor distribution. Meanwhile, Oike et al. (2006) demonstrated that AA activates the TRPM5 cation channel, which is a component of the sweet, bitter, and umami taste pathways of type II receptor cells. TRPM5-null mice showed no licking response to a sweet tastant, a diminished preference ratio for sweet and umami tastants, and a reduced response to bitter taste (Damak et al., 2006). Taken together, these data suggest that AA may serve as a flavor enhancer in type II receptor cells by modulating the TRPM5 channel.

We previously reported that the taste of Hinai-jidori chicken meat could be improved by dietary AAO supplements (Kiyohara et al., 2011). This finding is in good agreement with the hypothesis that AA may affect the perception of sweet, umami, and bitter tastes via the TRPM5 channel. In the present study, we confirmed that supplemental AAO improves taste of broiler chicken thigh meat, and that AA in meat affects the perception of umami taste. Moreover, this study suggests that AA content of broiler meat is directly proportional to AAO content in diets and may be used as a new index of the meat taste of chicken.

Glutamic acid (Glu) and inosine 5'-monophosphate (IMP) are well known taste active components of umami, and Glu and IMP salts are widely used as "flavor enhancers" (Yamaguchi and Ninomiya, 2000). Nishimura et al. (1988) analyzed the chemical components in meat and suggested that free amino acids (FAA) are responsible for improving the taste of meat during storage. Studies performed in the past 2 decades have compared the contents of FAA, including Glu, and IMP in Jidori and broiler meat. Karasawa et al. (1989) reported that the Glu content and total FAA content in the thigh meat obtained from 3 types of Jidori chickens was significantly higher than that in the thigh meat from broilers, whereas subsequent studies have reported no significant differences between the FAA contents of Jidori chickens and broilers (Fujimura et al., 1994, 1996). Moreover, Matsuishi et al. (2005) reported that soup prepared using broiler meat has a significantly higher FAA content than that prepared using meat from a Jidori, and the broiler soup tended to be more delicious than the Jidori soup. Fujimura et al. (1996) reported that the IMP content of the meat from Hinai-jidori chicken was significantly higher than that of the meat from broilers, whereas other studies have not revealed a significant difference in IMP content between Jidori and broiler chicken meat (Fukunaga et al., 1989; Karasawa et al., 1989). Taken together, these studies suggest that the FAA, Glu, and IMP contents are correlated with the taste of chicken meat; however, it has not yet been elucidated whether the differences in the contents of FAA, Glu, and IMP are actually correlated to the taste of Jidori chicken. In the present study, there were no significant differences in Glu and IMP contents among the group. There was no correlation between arginine content and sensory parameters, although a significant difference was observed in the arginine content among the groups. These data suggest that arginine, Glu, and IMP contents in broiler meat are not related to the sensory parameters.

Even though the taste of meat improves according to the amount of supplemental AAO, it is not economically viable to provide too much AAO supplement to broiler chickens. Since i) there were no significant differences in AA content and sensory analyses of thigh meat between $\mathrm{CO}$ and $1 / 8$ AAO groups, ii) the pairwise comparisons between the $\mathrm{CO}$ and 1/4 AAO groups, and between the CO and 1/2 AAO groups showed significant sensory differences, and iii) there was no major difference in the pairwise comparison between the 1/2 AAO and 1/4 AAO groups, we think that the 1/4 AAO dietary supplement, which yields thigh meat containing $0.98 \pm 0.05 \mathrm{mg} / \mathrm{g}$ of $\mathrm{AA}$, may be sufficient to produce sensory improvements over conventional broiler meat. Based on the content $(0.98 \mathrm{mg} / \mathrm{g})$ and the linear 
regression formula between dietary AAO content and AA content in thigh meat, $0.898 \mathrm{~g}$ of AAO per $100 \mathrm{~g}$ diet will be needed to obtain broiler meat with sufficient AA content to produce these effects.

In conclusion, we have shown that AA content in broiler chicken meat can be manipulated by dietary AA supplements, thereby improving the taste of broiler chicken. Our future studies will be directed towards analyzing the genetic background of Hinai-jidori and broiler chickens to understand why the AA content of Hinai-jidori chickens is higher than that of broiler chickens.

\section{REFERENCES}

Association of Official Analytical Chemists. 1990. Fat "crude" or ether extract in meat. Pages 931-932 in Official Methods of Analysis of the Association of Official Analytical Chemists (\#960.39). AOAC, Washington, DC, USA.

Brash, A. R. 2001. Arachidonic acid as a bioactive molecule. J. Clin. Invest. 107:1339-1345.

Cartoni, C., K. Yasumatsu, T. Ohkuri, N. Shigemura, R. Yoshida, N. Godinot, J. le Coutre, Y. Ninomiya and S. Damak. 2010. Taste preference for fatty acids is mediated by GPR40 and GPR120. J. Neurosci. 30:8376-8382.

Chaudhari, N. and S. D. Roper. 2010. The cell biology of taste. J. Cell Biol. 190:285-296.

Damak, S., M. Rong, K. Yasumatsu, Z. Kokrashvili, C. A. Perez, N. Shigemura, R. Yoshida, B. Mosinger Jr., J. I. Glendinning, Y. Ninomiya and R. F. Margolskee. 2006. Trpm5 null mice respond to bitter, sweet, and umami compounds. Chem. Senses 31:253-264.

Fujimura, S., T. Muramoto, M. Katsukawa, T. Hatano and T. Ishibashi. 1994. Chemical analysis and sensory evaluation of free amino acids and 5'-inosinic acid in meat of Hinai-dori, Japanese native chicken: Comparison with broilers and layer pullets. Anim. Sci. Technol. 65:610-618.

Fujimura, S., H. Koga, H. Takeda, N. Tone, M. Kadowaki and T. Ishibashi. 1996. Chemical compositions of pectoral meat of Japanese native chicken, Hinai-jidori, and broiler of the same and marketing age. Anim. Sci. Technol. 67:541-548.

Fukunaga, T., K. Koga, Y. Maita and S. Matsuoka. 1989. Free amino acid, carnosine and 5 '-inosinic acid contents in the breast and leg meats from the cross and triple-cross chickens of Satsuma native fowl (in Japanese). Bull. Facult. Agric. Kagoshima Univ. 39:223-232.

Gilbertson, T. A., D. T. Fontenot, L. Liu, H. Zhang and W. T. Monroe. 1997. Fatty acid modulation of K+ channels in taste receptor cells: gustatory cues for dietary fat. Am. J. Pysiol. Cell Physiol. 272:C1203-C1210.

Hatakeyama, G., A. Akamatsu, N. Hongou and M. Yatsuki. 1983. Improvement of growth and food utilization in Hinai-dori single-cross hybrids (in Japanese). Bull. Akita. Pref. Exp. St. Anim. Indust. FY1981:67-79.

Iverson, S. J., S. L. C. Lang and M. H. Cooper. 2001. Comparison of the Bligh and Dyer and Folch methods for total lipid determination in a broad range of marine tissue. Lipids 36:1283-1287.
Japan Oil Chemists' Society. 2009. The JOCS standard methods for the analysis of fats, oils and related materials, 1st English ed. Japan Oil Chemists' Society, Tokyo, Japan.

Karasawa, Y., K. Aoki and A. Hirakata. 1989. Free amino acids and purine compounds in leg and breast muscles from broiler, Satsuma, Satsuma cross and Kukin cross. Japanese Poult. Sci. 26:29-34

Kawai, T. and T. Fushiki. 2003. Importance of lipolysis in oral cavity for orosensory detection of fat. Am. J. Physiol. Regul. Integr. Comp. Physiol. 285:R447-R454.

Kiyohara, R., S. Yamaguchi, H. Ushio, M. Shimomura and T. Ichikawa. 2009. Effect of adding arachidonic acid to cooked foods (in Japanese). J. Cookery Sci. Jpn. 42:294-299.

Kiyohara, R., S. Yamaguchi, K. Rikimaru and H. Takahashi. 2011. Supplemental arachidonic acid-enriched oil improves the taste of thigh meat of Hinai-jidori chickens. Poult. Sci. 90:18171822.

Laugerette, F., P. Passilly-Degrace, B. Patris, I. Niot, M. Febbraio, J.-P. Montmayeur and P. Besnard. 2005. CD36 involvement in orosensory detection of dietary lipids, spontaneous fat preference, and digestive secretions. J. Clin. Invest. 115:31773184.

Matsuishi, M., A. Kato, N. Ishige, T. Hori, Y. Ishida, S. Kaneko, M. Takenonaka, Y. Miyamura, T. Iwata and A. Okitani. 2005. Comparison of meat palatability factors of Nagoya Cochin with broiler and Aigamo (in Japanese). Nihon Chikusan Gakkaiho 76:423-430.

Nishimura, T., M. R. Rhue, A. Okitani and H. Kato. 1988. Components contributing to the improvement of meat taste during storage. Agric. Biol. Chem. 52:2323-2330.

Oike, H., M. Wakamori, Y. Mori, H. Nakanishi, R. Taguchi, T. Misaka, I. Matsumoto and K. Abe. 2006. Arachidonic acid can function as signaling modulator by activating the TRPM5 cation channel in taste receptor cell. Biochem. Biophys. Acta. 1761:1078-1084.

Rikimaru, K. and H. Takahashi. 2007. A method for discriminating a Japanese brand of chicken, the Hinai-jidori, using microsatellite markers. Poult. Sci. 86:1881-1886.

Rikimaru, K. and H. Takahashi. 2010. Evaluation of the meat from Hinai-jidori chickens and broilers: Analysis of general biochemical components, free amino acids, inosine 5'monophosphate, and fatty acids. J. Appl. Poult. Res. 19:327333.

Science Council of Japan. 2006. Guidelines for Proper Conduct of Animal Experiments. Tokyo, Japan.

Yamaguchi, S. and K. Ninomiya. 2000. Umami and food palatability. J. Nutr. 130:921S-926S.

Yamaguchi, S., I. Tashima and N. Matsuzaki. 2005. Body taste improver comprising long-chain highly unsaturated fatty acid and/or ester thereof and vegetable fat composition containing the same. Japanese Patent No. 3729272.

Yamaguchi, S., I. Tashima and N. Matsuzaki. 2007. Vegetable fat composition containing long-chain highly unsaturated fatty acid and/or ester thereof. Japanese Patent No. 3962068.

Yamamoto, T., U. Watanabe, M. Fujimoto and N. Sako. 2009. Taste preference and nerve response to 5'-inosine monophosphate are enhanced by glutathione in mice. Chem. Senses 34:809-818. 